\title{
Cultivation of Compound Foreign-Related Talents under "Marine Economy"----from University's Perspective
}

\author{
Wu Yujing ${ }^{1}$, Liu Xiaodan ${ }^{2 *}$, Ren Ning $^{3}$ \\ ${ }^{1}$ Zhejiang Ocean University, Zhoushan, China \\ ${ }^{2}$ Lecturer of Foreign Language College, Zhejiang Ocean University, China \\ ${ }^{3}$ Zhejiang Ocean University, Zhoushan, China \\ *Corresponding Author: Liu Xiaodan, Lecturer of Foreign Language College, Zhejiang Ocean \\ University, China

\begin{abstract}
In 2016, the Zhoushan Archipelago New Area in Zhejiang Province was successfully upgraded from the Integrated Free Trade Zone to the only Free Trade Zone in the province (Zhoushan Zhejiang Free Trade Zone), the cultivation of high-quality compound talents with "marine-related specialty + foreign-related ability" will be more and more important. In the context of the scarcity of top local talents in the Free Trade Zone, this paper takes Zhejiang Ocean University as an example to explore the current situation of compound foreign-related talents training from the perspective of universities, thus to find deficiency with a view to further planning the future direction of development.
\end{abstract}

Keywords: marine economy, compound foreign-related talents, talents training, university

\section{INTRODUCTION}

The development of the marine economy has become an important focus of China in accelerating the transformation of the mode of economic development and in promoting the optimization and upgrading of the industrial structure. The 18th National Congress of the Communist Party made it clear that it is necessary to explore marine resources and build a marine potestatem. ${ }^{[1]}$ The unique abundance of marine resources in our country has laid a very solid foundation for the development of the marine economy. Under the background of marine economy trend, how to train high-quality compound foreign-related talents for the society has become a task that universities in China can not ignore. At present, there are 6 marine-related colleges and universities in China, of which Zhejiang Ocean University is the only university in Zhejiang Province that features the sea. Under the dual effects of "radiation and syphonage" brought by Shanghai Free Trade Zone ${ }^{[2]}$, Zhoushan Free Trade Zone is extremely lack of high-quality compound talents with "marine related specialty + foreignrelated ability". This research was conducted in the form of online questionnaires for students in Zhejiang Ocean University with the major of marine engineering, shipping, tourism management, marine science and technology, etc.60 questionnaires were issued in total, 55 were actually received and 52 were valid. The analysis is as follows:

\section{RESEARCH BACKGROUND}

Successfully upgraded from the Integrated Free Trade Zone to As the only Free Trade Zone in 2016, Zhoushan attracts a large number of foreign enterprises, such as the Boeing 737 Completion\& Delivery Center of the Boeing Company and the InterContinental Hotels Group PLC (IHG).The settlement of these companies, triggers a new shortage of high-quality compound foreign-related talents. The compound foreign-related talents under the marine economy are the top personnel's who can master the professional knowledge of the marine while being skilled in using one or more foreign languages. The training of such talents can not be separated from the government's policy guidance, enterprise staff training and teaching of colleges and universities. From the perspective of University, this paper will investigate the training mode of compound talents with "marine-related specialty + foreign-related ability" in Colleges and universities. Currently, there are three colleges and 
universities in Zhoushan, namely, Zhejiang Ocean University, Ocean College of Zhejiang University, and Zhejiang International Maritime College. Among them, Zhejiang Ocean University, as a veteran marine university, has a wide range of marine-related majors, a long history of development, and high quality students.

\section{SiTUATION ANALYSIS}

Among the 48 undergraduate majors in Zhejiang Ocean University, $72.91 \%$ are marine-related majors (including the direction of the sea), such as ship and marine engineering, port waterway and coastal engineering, maritime technology, etc, which accounts for $52.94 \%$ of the focal marine-related majors in Zhejiang province during the "12th Five-Year Plan" period, and all of them are equipped with English courses or English-related courses. The contents of this questionnaire involve all aspects of curriculums, syllabuses, professional qualities and comprehensive qualities of compound foreignrelated majors to explore the training model for high-quality compound talents with " marine-related specialty + foreign-related ability". The main findings are as follows:

\subsection{Marine-Related Professional Capacity-Building}

All marine-related major of Zhejiang Ocean University, such as marine science and marine engineering, will be required to take compulsory courses such as advanced mathematics and university physics in the first year to cultivate students' logical thinking .In the second and third year, the curriculum training system mainly focuses on professional courses. The aim of the establishment of these professional curriculums is to lay a solid foundation, enhance the students' professional knowledge and improve their core competitiveness; the curriculums are Marine Detection Signals and System Fundamentals, Ocean Remote Sensing Technology, Soil Mechanics and Foundations, etc. In the senior year, the school will begin to focus on practical training, connect students with society and enterprises, consolidate their knowledge with practice, and make them fit for the needs of the society.

To be specific, the positive interaction between school and enterprise is one of the important topics in the transformation of training mode in colleges and universities. Colleges and universities should understand the needs of employers information, graduate employment feedback information, followup survey of graduates. On this basis, the analysis of all kinds of information will enable teaching administrators, teachers and students to discover changes in enterprises and market in time, adjust teaching contents timely, and establish a good interaction mechanism between teaching and research

.${ }^{[3]}$ Every marine related major of Zhejiang Ocean University is equipped with a corresponding docking enterprise. For example, the school dispatches about 150 marine engineering students each year to Zhejiang Zhoushan Yihai Sea Shipping Co., Ltd., Yangfan group Limited by Share Ltd. for the internship. The company is a municipal backbone shipping enterprise. The company, founded in June 1956, mainly deals with coastal freight transport. It has 9 cruise ships, with 96,200 tons capacity. The company has two internal accounting units, they are ship repair plant and inflatable life raft maintenance station. Internships include graduation and recognition internships. In the process of internship, students can fully understand the structure of ships, marine engine equipment and the status of navigation on the sea. Through internships, students can effectively enhance their understanding of theoretical knowledge and promote the theory with practice. When it comes to the base instructors, they are experienced chief engineer, second engineer and ship maintenance engineer. Most of them have bachelor degree or above, and are rich in practical experience. They are professional enough to provide students with practical guidance. In the meantime, the school also dispatches professors and associate professors with higher academic qualifications. They instruct the students on-site the internships, so that the students can fully understand the use of marine machinery and marine navigation during the internship.

\subsection{Foreign-Related Comprehensive Ability Training}

In addition to the above-mentioned compulsory courses, ancillary courses and specialized compulsory courses, Zhejiang Ocean University also emphasizes the training of foreign language proficiency in maritime-related specialty. In addition to the regular English courses, the curriculum training system for the first and second year students also includes nautical English courses to enhance students' foreign language skills and acquire better professional knowledge. Through teachers 'imparting theoretical knowledge, students master the vocabulary of professional English, word skills and syntax 
structure, in simple terms, they master professional knowledge in English. The ocean is the open and inclusive bond between countries. If it is closed, and isolated from other countries, it would certainly be eliminated. Foreign languages are of extreme importance. Communication can not be effective if it is separated from the language, therefore, it is extremely important for those students specializing in marine affairs to acquire and even to master a foreign language. That is the reason why the university offers professional English courses for all marine related majors, and consciously develop students' foreign language researching ability; provide opportunities for international academic seminars, and make them distinguished from other marine-based talents and become high-quality compound talents with " marine-related specialty + foreign-related ability". Nowadays, having the theoretical knowledge alone or mastering the practical experience alone can not help keep a foothold in this society well. Therefore, "comprehensive ability" has been paid more and more attention to in the present society, and therefore Zhejiang Ocean University attaches more and more importance to cultivation of comprehensive Ability of foreign-related talents. In addition to the teacher training system of knowledge, such as foreign language knowledge and general education as mentioned in the above curriculum training system, teachers also improve students' comprehensive abilities in other fields through theoretical and practical training. For example, the university encourages every student to pass CET-6 under the premise of CET-4 by means of propaganda and education. Besides, the university also organizes various types of foreign language corners to enhance the students' relationship with overseas students while creating a good atmosphere for foreign language learning so as to make students aware of the importance of foreign language learning. Meanwhile, the university does not ignore the training of soft skills (Emotional Intelligence Quotient), exercise students' soft skills in the process of textual research, because the process of textual research not only exercises the IQ of the students, but also improves the ability of endurance very significantly. And they are required to obtain the certificate of National Computer Rank Examination, the People's Republic of China SEAFARER'S PASSPORT, Familiar and Basic Safety Training Certificate, Proficient in Survival Craft and Rescue Boat Training Certificate, Senior Fire Training Certificate, Proficient in First Aid Training Certificate and other professional certificates. To this end, the university holds knowledge contests to select excellent students to have competitions at the provincial and national level. In addition, the university launches the power of role models by inviting outstanding graduates and outstanding social workers in the industry to give lectures to the students, thus to impart experiences and create a good atmosphere for learning, and constantly urges students to improve their comprehensive qualities.

\section{ANAlysis Of DeFicienCy}

\subsection{Emphasizing Theoretical Education and Lacking Practice in the Training of Professional Competence}

After the questionnaire and other forms of research, the following deficiencies can be found: teachers still lay emphasis on traditional teaching of theoretical knowledge; the teaching mode is not diversified enough; there lacks practical ability training. Although there are practical curriculums, the proportion is not large enough, and the traditional way of lecturing is still the main pattern. From the first to the third year in college, including the summer and winter vacation, the school has not arranged the students to take part in the internship. In the graduation internship and cognition internship of the fourth year in college, the opportunities, namely the internship quota is limited, many students can not enjoy good practical education resources, so that social information exchange is not timely. The training of talents in the school deviates from the society's market orientation, which is not conducive to the future employment development of the students.33\% of the students surveyed said they will not be engaged in foreign-related jobs in the future (Marine-related Posts plus foreign languages as one of the working languages).From this aspect we can say that this is also a waste of education resources.

\subsection{Lack of Guidance for the Training of Foreign-Related Ability}

The cultivation of compound foreign-related talents under the "marine economy" is simply the training mode of "foreign language + major", "major + foreign language" or "double degree". ${ }^{[4]} \mathrm{At}$ present, the fresh graduates who possess both solid maritime expertise and outstanding foreign language ability of speaking, listening, reading and writing are comparable to the rare diamond in the 
job market. However, as far as the ability of foreign languages is concerned, the weak proficiency of foreign language of marine-related engineering students is still a major disadvantage in searching for employment opportunities. Only $24 \%$ of the students surveyed were satisfied with the college foreign language learning (such as the college foreign language class / foreign language corner / class taught by foreign teachers, etc.). In Zhejiang Ocean University. Except for the CET(College English Test Band 4 and Band 6) which all the university students participate in and NECCS (National English Competition for College Students) contest that the school advertises, the remaining English proficiency certificate test like CATTI (China Accreditation Test for Translators and Interpreters), Shanghai Foreign Language Interpretation Certificate Examination, IELTS(International English Language Testing System), TOEFL(The Test of English as a Foreign Language),Zhejiang Ocean University does not play a good role in guidance. In fact, the above examinations have many benefits for the development of advanced foreign language proficiency. Secondly, all the sea-related professional students' foreign language proficiency is based on traditional written assessments, and there are few practical demonstration-based assessments, resulting in many students' foreign languages becoming "dumb", which are confined only to the written form.

In terms of foreign exchanges between universities, there are still a few talent exchange opportunities and limited funding for schools. For example, the exchange universities docking in the autumn of 2017 of School of Port and Transportation Engineering are University of Strathclyde (UK),National Kaohsiung Marine University(Taiwan),National Taiwan Ocean University(Taiwan),National Penghu University(Taiwan),South Ural State University (Russia).Zhejiang Ocean University can send a total of 65 sophomores and juniors to foreign exchange universities, and 45 of them go to South Ural State University in Russia, and there are only five or six exchange positions for the other four universities, which are very limited. The total number of students in the School of Port and Transportation Engineering is 674 , and the exchange quota is only $9.6 \%$ of the total number of all the students. Besides, 4 students are funded by public fees, 5 students are free from tuition fees, and 3 are funded by 25 thousand RMB (RenMinBi), and the rest of the students are required to pay on their own expenses. It shows that funding for college exchanges are still not enough.

\section{ANALYSIS OF METHODS}

\subsection{Stressing the Importance of Technical Skills}

Universities should not provide theory for its own sake, but give practical training to students, thus to take its social responsibility. Vocational education and training can provide students with practical skills which prepare them for employment. Zhejiang Ocean University let the first, second and third year majors only learn theoretical knowledge and does not fully use the class time to give students opportunities to get to know about the situation of company in the society. Universities should not only maintain high academic and research standards, but also prepare competitive workforce for the society to meet the labor demands for the future economic growth. So, Zhejiang Ocean University should take some measures to improve this situation.

For example, firstly, it is better for school to arrange some activities for freshmen to visit some professional-related local businesses companies, so that students can have a general understanding of their major-related social work and overall view toward the future job direction. According to the result of the questionnaire survey, many students do not have a very clear understanding of their majors, this is one of the reasons why they have achieved less in the four years of college life, so visiting professional-related local companies in the first year will be beneficial.

Secondly, in the second year of study, school can give " marine-related specialty + foreign-related ability" students some social practice assignments. Students are required to use the time of winter vacation and summer vacation to visit some relevant companies (not limited to local companies, some major companies are also welcomed) and investigate employers' requirements for marine-related talents with foreign language ability, including the quantity of talent demand and the requirements of professional skills. This approach will enable students to better understand their own direction of work and their own deficiencies, and let them know more about their own abilities and social requirements for talent, so that students' efforts are more efficient. 
Fourthly, in the junior year, it is better for university to lead the teaching of "the third classroom" teaching and combine "the third classroom" teaching with "the first classroom" teaching, so that the students will realize their social responsibilities earlier and apply the theoretical knowledge to practice more effectively. Anyway, technical skills really matter in the employment market, Zhejiang Ocean University should attach more importance to them.

\subsection{Attaching More Importance to Soft Skills}

With the advent of economic industry transformation and upgrading, mass entrepreneurship, innovation, and the arrival of the "Internet Plus" era, requirements of workforce have changed from single skilled talents to comprehensive talents with both hard and soft skills. Students must have both hard skills and soft skills, which can adapt to the needs of the development of the times. Soft skills play a decisive role in the sustainable development of students' careers. ${ }^{[5]}$ The higher the value of the soft skill, the stronger the ability to deal with things. It is a scale to measure the ability of a person to deal with things. ${ }^{[6]}$ It is not comprehensive enough for the school to train students' soft skills only through textual research. The cultivation of soft skills should be paid more attention in today's society, especially in colleges and universities, which the personality are very easy to be formed and shaped due to the freer academic atmosphere. However, most college students are in adolescence, their ideas are not mature, and their behavior can easily become extreme. They need someone to help them understand their own personality traits, enhance their social skills, like their ability to communicate with others, their language skills, thus help them form the well-formed personal behavior. Recognize yourself - proactive - efficient self-confidence - win cooperation - improve impact - strain growth. ${ }^{[6]}$ The emphasis and training of soft skills will enable students to practice hard skills more effectively, thus to make them become successful more easily. Zhejiang Ocean University can hire experts at home and abroad to give lectures or training to students to improve their Emotional Intelligence Quotient. At the same time, some social skills training related to "marine-related specialty + foreign-related ability" can also be held in schools to improve students' soft skills in a targeted manner. If a marine-related talent with foreign language ability is low in the soft skills, he cannot fully achieve his potential in professional skills, so Zhejiang Ocean University should attach more importance to the soft skills of marine-related talents with foreign language ability.

\subsection{Cultivating Students' Foreign-Related Ability Systematically}

In practical communication, language activities take place in an integrated form. The completion of an activity usually requires the simultaneous use of various language knowledge and multiple language skills. Therefore, in the foreign language teaching, the curriculum should ensure the coordinated development of knowledge transfer and skill training, and strengthen the connection between individual skills such as listening, speaking, reading and writing, and promote the synthesis of activities such as hearing, speaking, seeing, and writing. From the beginning of the freshman year, the cultivation of foreign language skills for marine-related talents should be more systematic and more instructive. Systematic foreign language teaching is a system highly integrated with a high degree of unity in teaching principles, syllabus, teaching methods, writing and use of teaching materials, and the quality of teachers. ${ }^{[7]}$ The first is systemic in the time dimension, universities should have a clear timetable on the cultivation of foreign language abilities of the marine- related talents. For example, in the first year, universities should focus on laying a solid foundation and correcting the pronunciation, because in the face of national enrollment, the foreign languages ability of students from all over the country is not just the same, and also they have different accents. Therefore, the students who have weak foundation should be paid relatively more attention to in the foreign language teaching of freshmen. At the same time, as for marine-related students with a good foundation in foreign languages, schools can encourage them to participate in foreign language competitions and related foreign language examinations. On the one hand, they can better understand their own abilities, and on the other hand, if they do well in those activities, their self-confidence and self-esteem could be enhanced, which will be very beneficial for their future development. During the second and junior year, school should fully strengthen the promotion of foreign language-related certificates, which have high social recognition. In the process of applying for employment, the certificate of the applicant is also one of the focuses of the employer's attention, so having certificates with high social 
recognition can increase students' employment competitiveness. In addition to the promotion of certificates, schools can also organize more foreign language competitions to encourage students to participate. On the one hand, it can stimulate students' enthusiasm for learning a foreign language. On the other hand, it can also enable schools to discover more talented students.

\subsection{Enhancing Talent Exchange between Universities}

Years of practice have shown that for many colleges and universities, especially a large number of non-key colleges and universities, it is relatively rare for them to participate in national exchanges and cooperation in teaching reform. Because of various reasons, they have less chance to communicate. And these schools need more communication, collaboration and improvement. How to solve this problem, regional university cooperation can better alleviate this conflict, and it is easier to mobilize the enthusiasm of a large number of non-key universities. ${ }^{[8]}$ So it is better for Zhejiang Ocean University to improve the regional and international university cooperation. The communication between colleges and universities can help each other know more about the level of teaching reform at the same level, thus to learn from others' strong points and make the gap narrower. The relevant departments of Zhejiang Ocean University should strengthen the communication with other colleges and universities, especially those in foreign countries, and strive to provide more opportunities for foreign exchange for the marin-related talents. Because going abroad can not only help them understand foreign cultures, but also broaden their horizon, and more importantly, frequently using foreign languages as tools to communicate will definitely develop their ability of foreign language, especially their oral skills.

\section{CONCLUSION}

Compounding personnel training on" marine-related specialty + foreign-related ability" talents is a long-term and arduous task. Colleges and universities must adapt to changes in the market economy and make corresponding changes to provide society with qualified talents. Compared to domestic developed marine economic cities, the level of foreign development in Zhoushan is still relatively low at present, and there is a huge gap in the talents with "marine-related specialty + foreign-related ability". Zhejiang Ocean University should seize this opportunity to perfect the evaluation model for foreign-related talents involved in marine field, thus to give a new future for the marine economy, and to build a comprehensive talent development and training system. In this way can Zhejiang Ocean University take up social responsibility and provide more compound foreign-related talents for the society.

\section{REFERENCES}

[1] State Oceanic Administration Learns the Spirit of the Eighteenth CPC National Congress and Deploys the Next Step

[2] Wang L,Study on the Declaration of Free Trade Zone in Zhejiang Province -- from the Perspective of the Declaration of Zhoushan Free Trade Port. China Business \& Trade,No.17, Pp29-31(2014)

[3] Fan S, Liu Y, Study on Strategy of Foreign Talents Development under Coastal Strategy. Journal of Taiyuan Urban Vocational College,No.3, Pp30-31 (2014)

[4] Miao X,Research and Practice on the Training Mode of Compound Foreign Language Talents. Course Education Research, No.1,Pp113-114( 2016)

[5] Zhong B, Exploration and Practice of Construction of Soft Skill Training Base in Vocational Colleges. Journal of Zhejiang Institute of communications, No.2,Pp71-74(2017)

[6] Baidu baike

[7] Mei D, On Systematic Foreign Language Teaching. Foreign Language Education, Pp72-73(1990)

[8] Lv Y, Yuan S,Study on the Exchange and Cooperation of Regional Universities. China Higher Education Research, No.4,P77(1999) 

Perspective

\section{AUTHORS' BIOGRAPHY}

WuYujing, born in 1996, Chinese. She is a junior of Foreign Language College,
Zhejiang Ocean University, majoring in English.

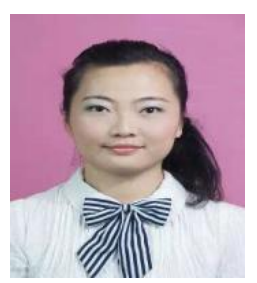

Liu Xiaodan, Lecturer of Foreign Language College, Zhejiang Ocean University, China. Research area: English translation and interpretation.

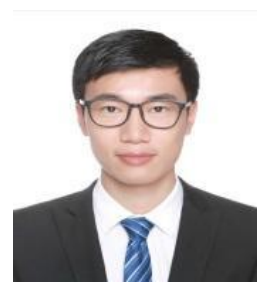

Ren Ning, born in 1995, Chinese. He is a senior student of Foreign Language College, Zhejiang Ocean University, majoring in English.

Citation: Wu Yujing, Liu Xiaodan, Ren Ning. " Cultivation of Compound Foreign-Related Talents under "Marine Economy"----from University's Perspective." International Journal of Humanities Social Sciences and Education (IJHSSE), vol 5, no. 4, 2018, pp. 76-82 doi: http://dx.doi.org/10.20431/2349-0381.0504008.

Copyright: () 2018 Authors. This is an open-access article distributed under the terms of the Creative Commons Attribution License, which permits unrestricted use, distribution, and reproduction in any medium, provided the original author and source are credited. 